\title{
Perceptions and Uses of Digital Badges for Professional Learning Development in Higher Education
}

\author{
Patti Dyjur $^{1}$ (D) Gabrielle Lindstrom ${ }^{1}$
}

Published online: 10 March 2017

(C) The Author(s) 2017. This article is published with open access at Springerlink.com

\begin{abstract}
Few instructors in higher education have completed a formal teaching program and, therefore, rely on informal professional development opportunities to enhance their teaching practice. Micro-credentialing in the form of digital badges is one way in which instructors can document their non-credit learning and accomplishments. This mixed methods research study was conducted to gauge participants' perceptions and anticipated uses of digital badges. Results of the study indicated that many participants had positive perceptions of the badges, finding them authentic and innovative. Some participants had negative or mediocre perceptions of digital badges, finding them less prestigious than a certificate of completion. Badge appearance may have had an impact on perceived credibility. Participants intended on using their digital badges in a variety of ways, such as sharing on social media and job searches. Many found the badges motivating and persevered to complete a program; however, they did not do this solely to earn a badge.
\end{abstract}

Keywords Digital badges · Higher education ·

Micro-credentialing $\cdot$ Motivation $\cdot$ Professional learning development $\cdot$ Teaching development

The use of digital badges is relatively innovative in higher education, and made possible by recent technological advances, particularly in the area of professional learning

Patti Dyjur

pdyjur@ucalgary.ca

Gabrielle Lindstrom

gabrielle.lindstrom@ucalgary.ca

1 University of Calgary, 434 Collegiate Boulevard NW, Calgary, AB T2N 1N4, Canada development. As such, there is scant literature on the topic. This study will help to illuminate the perceptions and uses of digital badges by instructors and graduate students who have completed professional development activities to advance their knowledge of teaching in higher education. We begin with a review of the literature, and outline our mixed methods design-based research study. After reporting our findings, we discuss them in relation to current literature. We close the paper with recommendations for others to consider if implementing a similar platform in their institution.

\section{Literature Review}

What are Digital Badges and how are They Used in Higher Education? Digital badges (also referred to as "badges" in this paper) are "a symbol or indicator of an accomplishment, skill, quality or interest... used to set goals, motivate behaviors, represent achievements and communicate success in many contexts" (Mozilla Foundation 2012, p. 3). Metadata are embedded in digital badges that have information about the name of the issuing institution, the date issued, and criteria for earning the badge (Fields 2015). In addition to providing a visual record of achievement, digital badges can be shared through social media and professional networking sites. They can be added to a digital portfolio, and many can be printed off and added to a physical portfolio. Because they contain information about what was accomplished in order to receive the badge, they provide more detailed information about what the recipient learned than a traditional paper certificate (Devedzic and Jovanovic 2015; Elliot et al. 2014; Mehta et al. 2013).

Digital badges are a form of micro-credentialing, which provides a way to recognize and evidence accomplishments acquired through informal learning experiences at a more 
granular level than is captured by courses or degrees (Gamrat et al. 2014). In higher education they are therefore useful in capturing learning that might otherwise go unrecognized through formal academic accreditation processes (Devedzic and Jovanovic 2015). Often compared to a visual narrative of achievements, micro-credentialing through the use of digital badges allows individuals to document their professional learning development attained through stand-alone workshops and seminars. People select and sequence the informal (non-credit) learning opportunities they want in order to create their own personal learning pathway (Cucchiarra et al. 2014; Gamrat et al. 2014).

\section{Advantages and Disadvantage of Using Badges in Higher} Education Digital badges offer several advantages in a higher education context. They can provide a list of competencies attained, the date, and an expiry date for each attainment as applicable. They can also document informal learning accomplishments received outside of credit programs in a way that is more flexible than traditional methods such as paper certificates and transcripts (Devedzic and Jovanovic 2015). Elliot et al. (2014) argue that digital badges capture a more holistic, accurate picture of educational achievement in comparison to traditional degrees or certificates. Moreover, skill recognition is often missing or lesser valued in formal academic contexts (Mozilla Foundation 2012). Ahn et al. (2014) maintain that a college or university degree cannot capture all the knowledge, skills and accomplishments that a graduate has, but digital badges can provide detailed information on a larger number of learning accomplishments than is possible on a course level. For example, Mehta et al. (2013) assert that microcredentialing in the form of digital badges has the potential to drastically change the field of medical education by providing a more detailed framework to assess students' knowledge and skills, provide evidence for their learning, and demonstrate this competence to others.

Digital badges can facilitate an individualized learning pathway, particularly critical for professional learning development in fields that are rapidly changing and where formal programs may not be in step with emerging trends, technologies and practices (Fields 2015). From a continuing education perspective, Janzow (2014) asserts that digital badges can help individuals to set goals, evidence their qualifications, and share accomplishments with professional networks. They may also be valuable to issuing institutions from a marketing perspective (Finkelstein et al. 2013).

As with most educational innovations, there are possible disadvantages in using digital badges. A barrier associated with digital badge usage is determining how to make them more authentic since they may not appear as credible to potential employers as a paper credential from a recognized post-secondary institute (Glover 2013). Moreover, digital badges may have an effect on learner motivation for some
(Abramovich et al. 2013; Ahn et al. 2014; Cucchiarra et al. 2014; Finkelstein et al. 2013; Gibson et al. 2013). Finkelstein, Knight and Manning (2013) claim that digital badging optimizes the reward pathways of the brain; however, they warn that "there is a very real risk of alienating otherwise well-intentioned, self-motivated learners by holding a badge in front of them as the reason to pursue a learning opportunity" (p. 19). Abramovich et al. (2013) found that badges in which both participation and skill are recognized may be more effective in increasing overall learner motivation. Moreover, providing information to students regarding the type of digital badge they will earn prior to the start of a set learning activity may also increase motivation. Their study compels us to ask what types of learners respond best to badges and, once this is established, matching badges with learner motivation and rewards will become less difficult.

\section{Shifts and Trends}

Within the context of higher education, digital badges represent a change in approach to how accomplishments in professional learning development are appraised. Traditionally, they have been measured by the amount of time spent in training, or perhaps by participation in a program. Digital badges represent a shift from attendance-based certificates to criteriabased accomplishments. Rather than automatically receiving a certificate for attending a program, participants must meet a learning outcome, demonstrate their learning in some way, or meet certain criteria in order to receive a digital badge (Casilli \& Knight 2012). Hart (2015) states that because there are few higher education institutions currently implementing digital badges for the purpose of professional learning development, it is unclear if digital badges are effective, and if so, what constitutes good practice.

A review of the literature points to the need to better understand the use of digital badges in higher education. In this study we explore the role of micro-credentialing within the context of professional learning development through the use of digital badges. In particular, we examine perception and usage through the following research questions: How do participants perceive digital badges? How do they intend to use digital badges?

\section{Methods}

A design-based approach was used for the study, with data collected through mixed methods procedures. This approach was well suited as it allowed the researchers to identify both strengths and weaknesses of the digital badges in order to improve the micro-credentialing initiative while addressing 
our research questions. Employing a design-based methodology also proved effective for mixed methods, iterative cycles of data collection, and refining a real-life complex educational initiative (Anderson and Shattuck, 2012).

After completing a professional learning program in which a digital badge was offered, all registrants were invited to participate in the study. Participants were recruited in person and online through email. Data were collected through semistructured interviews, and an online survey with both Likertscale and open-ended survey questions. Questions related to how participants perceived and intended to use their digital badge. Three in-depth interviews were conducted, and sixteen participants answered the survey. Descriptive statistics were tabulated for all Likert-scale questions and open-ended responses were analyzed according to theme. Interviews included all of the registrants who volunteered to be interviewed, including one participant who opted not to complete the final assignment in a program and therefore did not earn a digital badge. Interview data were analyzed using thematic coding.

Participants in the study consisted of instructors and graduate students who took a program or workshop related to professional learning development at a Canadian higher education institution on a voluntary basis. They had the opportunity to earn a digital badge by meeting specific criteria relating to learning and accomplishments upon completion of the program. Not all participants received a digital badge; two of the respondents did not meet the criteria to earn one. Badges were offered for three different programs relating to teaching development in higher education: a teaching program for graduate students, a course design program, and a program focused on learning to teach online. The programs were offered in different formats, with the graduate teaching certificate in a traditional face-to-face format, the teaching online program offered entirely online, and the course design program offered in blended format. All three programs required participants to evidence their learning in order to earn a digital badge; attendance or participation were not sufficient. For example, the course design program required participants to write course outcomes, create an assessment blueprint, and design a course (University of Calgary 2015). Participants earned one badge upon completion of the entire program.

We decided to develop the platform that was used to offer the digital badges in-house, so that we could customize it to our needs and incorporate additional features at a later time. Badges were delivered through the site by the program administrator, who kept track of the participants that had fulfilled the criteria and earned a badge. Recipients received an email outlining the steps to retrieve their badge, which could then be viewed on the site (http://badges.ucalgary.ca/), added to Mozilla Backpack ${ }^{\mathrm{TM}}$, LinkedIn ${ }^{\mathrm{TM}}$, Facebook ${ }^{\mathrm{TM}}$, and Twitter ${ }^{\mathrm{TM}}$, downloaded as a PDF file and printed as a hard copy. Recipients who required support for retrieving their badge could find information on the platform or ask their program administrator in addition to the email instructions. For the three programs included in the study, a total of 81 digital badges were issued in 2015, and 44 issued in 2016.

\section{Results}

Quantitative Results Table 1 provides quantitative information on survey respondents' perceptions of digital badges. Generally, the results show that participants had a positive perception of their digital badges. Most (87.5\% strongly agree + agree) were happy to receive a digital badge for completing their program or workshop, and a large percentage felt

Table 1 Participants' perceptions of digital badges

\begin{tabular}{|c|c|c|c|}
\hline & $\begin{array}{l}\text { Strongly Agree + Agree } \\
\text { No. }(\%)\end{array}$ & $\begin{array}{l}\text { Not Sure } \\
\text { No. }(\%)\end{array}$ & $\begin{array}{l}\text { Strongly Disagree + Disagree } \\
\text { No. }(\%)\end{array}$ \\
\hline $\begin{array}{l}\text { I was happy to receive a digital badge for } \\
\text { completing a professional development program. }\end{array}$ & $14(87.50)$ & $2(12.50)$ & $0(0)$ \\
\hline I felt encouraged when I received the badge. & $12(75.00)$ & $2(12.50)$ & $2(12.50)$ \\
\hline I felt motivated when I received the badge. & $10(62.50)$ & $5(31.25)$ & $1(6.25)$ \\
\hline I want to earn more badges from this institution. & $11(68.75)$ & $3(18.75)$ & $2(12.50)$ \\
\hline I want to earn more badges from other institutions. & $8(50.00)$ & $5(31.25)$ & $3(18.75)$ \\
\hline The badges seem authentic to me. & $9(56.25)$ & $3(18.75)$ & $4(25.00)$ \\
\hline $\begin{array}{l}\text { I would rather earn a badge than a certificate of } \\
\text { completion (on paper) for professional } \\
\text { development activities. }\end{array}$ & $2(13.33)$ & $8(53.33)$ & $5(33.34)$ \\
\hline The badges seem credible to me. & $10(62.50)$ & $2(12.50)$ & $4(25.00)$ \\
\hline I am satisfied with the digital badge I received. & $13(75.00)$ & $3(18.75)$ & $1(6.25)$ \\
\hline $\begin{array}{l}\text { I feel that the digital badge is recognition of the } \\
\text { program I completed. }\end{array}$ & $14(87.50)$ & $0(0)$ & $2(12.50)$ \\
\hline I worked extra hard to earn the badge. & $11(68.75)$ & $2(12.50)$ & $3(18.75)$ \\
\hline
\end{tabular}


encouraged $(75 \%)$ and/or motivated $(62.5 \%)$ to earn the badge. There was a high level of satisfaction with the badges $(75 \%)$, many worked extra hard for their badge $(68.75 \%)$, and most participants felt the digital badge was recognition of the program they completed $(87.50 \%)$. Many participants $(68.75 \%)$ wanted to earn more badges from their current institution, while some (50\%) wanted to earn more badges from other institutions.

The quantitative data show that not all perceptions of the digital badges were positive, however. A relatively high number of participants $(25 \%)$ stated that they did not perceive the digital badges to be authentic. Some (33.34\%) disagreed with the statement that they would rather have a digital badge than a paper certificate of completion, and slightly more than half of participants $(53.33 \%$ ) were unsure if they would rather have the digital badge or the paper certificate.

Table 2 provides quantitative information on survey respondents' intended uses of digital badges. Many of the respondents $(50 \%)$ indicated that they would print off the PDF file associated with their digital badge, and two-thirds $(66.67 \%)$ stated that they would use the digital badge in conjunction with a physical portfolio to document their professional development work. Few of the respondents intended on sending the link for their badge to others such as potential employers $(25 \%)$ or adding the badge to a Mozilla Backpack $^{\mathrm{TM}}$ account (12.5\%).

Qualitative Results Analysis of the qualitative data yielded six themes regarding perception and use of digital badges: varying first impressions, authentic and innovative, less prestigious than a certificate, impact of the badge design on credibility, increased motivation, and a variety of intended uses. The first theme to emerge from the data was that participants had a wide variety of first impressions about their digital badge. While some were happy and encouraged, some were neutral about it or viewed their badge as juvenile and others were curious about it as they had not encountered a digital badge before. One interview participant noted that he or she felt proud and had a feeling of accomplishment (P1).

Second, two of the interview participants and more than half of the open-ended survey question respondents stated that they viewed their digital badge as authentic, credible and/or innovative. One participant felt that the digital badge was more professional than a paper certificate of completion that people sometimes receive upon completing a professional development program. According to another, it is "something you can always refer to and feels more authentic" (P8). Two interview participants said that digital badges were creative or innovative as they were easier to add to a digital portfolio and share with others through social media. These participants were pleased with the flexibility of use that digital badges offer.

One interview participant and one survey respondent noted that digital badges include more detailed information than a paper certificate, by making the accomplishment more tangible and transparent. According to one participant, the digital badge system supported his or her ongoing professional development in that:

I'm able to say, 'look, here's a lists of things I finished and this is what I received to prove that I actually finished it.' With the [badge] there's a list of objectives of what you're going to complete and what you will get out of it. So you take that and you plug it into your CV...to show what you have now based on this program. I was able to see what I was going to get out of it (P3).

Another participant stated that the list of learning outcomes associated with the digital badge made expectations more explicit; also, understanding how their work in the program would be assessed was particularly valued. One interview participant stated that having informal, incremental learning recognized in this way gave him or her additional incentive to complete the program (P1).

The third theme that emerged, in contrast to the second, was that some participants found their digital badge to be less

Table 2 Participants' intended uses of digital badges

\begin{tabular}{llll}
\hline & $\begin{array}{l}\text { Strongly Agree + Agree } \\
\text { No. }(\%)\end{array}$ & $\begin{array}{l}\text { Not Sure } \\
\text { No. }(\%)\end{array}$ & $\begin{array}{l}\text { Strongly Disagree + Disagree } \\
\text { No. }(\%)\end{array}$ \\
\hline $\begin{array}{l}\text { I will print the PDF file as a certificate to add to a physical } \\
\text { portfolio (such as a work portfolio or annual performance } \\
\text { review). }\end{array}$ & $8(50.00)$ & $6(37.50)$ & $2(12.50)$ \\
$\begin{array}{l}\text { I plan on using digital badges in conjunction with a portfolio } \\
\text { of work or artifacts to document my professional } \\
\text { development work. }\end{array}$ & $10(66.67)$ & $3(20.00)$ & $2(13.33)$ \\
$\begin{array}{l}\text { I intend on sending a link to the badge or my portfolio to } \\
\text { others (such as potential employers). }\end{array}$ & $4(25.00)$ & $9(56.25)$ & $3(18.75)$ \\
$\begin{array}{l}\text { I will send the badge to my Mozilla Backpack } \\
\text { TM account. }\end{array}$ & $2(12.50)$ & $7(43.75)$ & $7(43.75)$ \\
\hline
\end{tabular}


prestigious than a paper certificate. One interview participant and several survey respondents felt that a digital badge was less credible. One person noted that the value of the digital badge was tied to the university and doubted whether it would be acknowledged beyond the issuing institution:

I might apply for a $\mathrm{PhD}$, which is another reason why I wanted to do a badge. Maybe it will be better for my $\mathrm{PhD}$ application but if I apply at a different university for example, the result could be, 'oh a badge from the University of XXX, we don't know this university. This badge means nothing to us.' (P1)

Fourth, the badge design seemed to have an impact on how the badges were perceived. Several people mentioned badge design, especially the member badge that was automatically issued when they registered on the site. The simplistic design of the member badge was off-putting for some and lowered the credibility of the program, as stated by both interview and survey participants. While the badge that participants earned in the program was generally well received, the member badge was "not aesthetically pleasing" (P7) and needed a more modern look (P4). Participants felt the badges needed to be distinguished looking, more professional in appearance than simple designs (P3).

The fifth theme to emerge from survey and interview comments was that many participants found the badges motivating, but not by themselves. Participants said they did not take the professional learning program in order to receive a digital badge, but rather, for reasons such as career advancement (P3), to increase job opportunities (P1 and P2), or to learn more about teaching in higher education (P9). However, one interview participant noted that the badge provided additional incentive to finish up assignments in the program (P1).

Sixth, participants noted that they had already used their badges in a variety of ways and intended to use them in others, including adding their badge to their resume, listing or linking it to their annual performance review, printing it to use as a paper certificate or put in a physical portfolio, sending the badge link to others such as potential employers, sharing with others through social media sites, or posting to their websites. A survey respondent mentioned that the flexibility of digital badges could be useful when searching for a job:

It seems like this might be a more convenient way to display my training in the various online platforms (eg. LinkedIn $^{\mathrm{TM}}$, Research Gate ${ }^{\mathrm{TM}}$, Academia.edu ${ }^{\mathrm{TM}}$ ) that are continuously growing and replacing or augmenting traditional networking and job search documents (P9).

Some participants mentioned that they would refer to the badge description when writing their accomplishments on a resume, or to help determine gaps in their knowledge of teaching in higher education and consequently look for professional development opportunities. Others did not know how they would use their badge, if at all. Some people had no prior experience with digital badges and were unsure about possible uses. Others were familiar with the concept of digital badges, but had not considered how they would use the one they earned.

\section{Discussion and Recommendations}

The number of participants in the study to date is small, and we anticipate that more data will be collected. Therefore the findings must be considered preliminary and within the context of non-credit professional learning opportunities in higher education. Nevertheless, the discussion may be salient to others considering the use of digital badges in a similar context, with initial results of the study pointing to several recommendations for practice.

Both quantitative and qualitative data suggested that participants had generally positive perceptions of the digital badges. This finding supports the continued use of digital badges for professional learning opportunities in higher education. Similar to our findings, Glover and Latif (2013) noted that the use of badges in higher education was motivational in that they offered alternative ways of recognizing learning achievements.

Not all participants had a positive first impression of digital badges though. Several of the respondents were ambivalent about them or viewed them as juvenile. This is consistent with McDaniel et al. (2012) finding that some students in an online credit course were unenthusiastic about earning badges for tasks such as posting to the discussion board or taking a quiz.

While many participants viewed their digital badge as credible and authentic, this finding may be tied to the badge's design and appearance. Badges that were simplistic or juvenile-looking were perceived as less credible, and two participants noted that they wanted a professional, distinguishedlooking digital badge. We suggest that putting effort into the graphic design of the badge is worthwhile as the icon design could have an impact on the program or initiative's credibility and perceived professionalism. Crude or simplistic badge designs run the risk of being perceived as juvenile.

Some participants felt that the digital badge was less credible than a paper certificate. The finding could be related to the assertion that some employers question the credibility of digital badges (Devedzic and Jovanovic 2015). It also revealed a misconception that some participants had about their badges in that they did not realize they could download a file and print off a certificate with the same information as a traditional paper certificate. Similarly, Law and Law (2014) found that "learners do not always find the display of a digital badge to 
be easy to grasp" (p. 12). Therefore, one possible solution would be to offer participants the choice of a digital badge or a paper certificate when they complete a program.

Participants generally found their badge to be motivational to complete the work of a professional development program but not to register for another one. This is encouraging in that it appears as though digital badges have the potential to positively impact on participants' learning behaviours. In their 2013 study, Abramovich, Schunn and Higashi determined that the digital badges had a different motivational effect on learners depending on their specific prior knowledge. It is worth noting though that their study was conducted with seventh and eighth-grade participants.

The data also indicated that participants were thinking about using their digital badges in several different ways, including adding to a digital or physical portfolio, sharing through social media, and including them on a resume. Purposes varied as well, including evidencing their learning for annual performance processes or job searches, displaying accomplishments to peers, tracking and identifying opportunities for professional learning, and augmenting traditional networking opportunities. This finding indicates that it is essential to have a flexible badging system with some degree of user control, which is consistent with Janzow's (2014) stance. Janzow (2014) suggests that a versatile badging system is essential so that it can evolve based on the needs of users and badge issuers. Badge recipients need the option of being able to print off badge details, share their badges on different social media and networking sites, and have control over displaying and hiding different badges they receive. Additionally, people want to track their accomplishments over time. Therefore, a system that is exclusively for people who currently have a role at the institution will be too limiting, excluding users who graduate or find employment elsewhere. For long-term use, ensure that digital badges are not tied to institutional email addresses or proprietary institutional software. We also recommend that the badging platform allows for some user flexibility and control, including downloading a file and printing a certificate, sharing through social media, adding them to professional networking sites, and activating or hiding individual badges.

Quantitative and qualitative data supported the finding that some people do not fully understand what digital badges are or how they might be used. Lack of familiarity with digital badges and their features is not surprising: Ahn et al. (2014) found that, as a pedagogical tool, micro-credentialing through the use of digital badges is still in the emergent stages. Over time, more experience with digital badges and examples from others will help to illuminate many of their features. In the meantime, possible ways to provide information and address misconceptions are to demonstrate how they might be used, include an email address on the micro-credentialing site to which workshop participants can send their questions, provide a summary sheet for future reference, and inform facilitators of the programs about digital badges so that they can accurately answer any questions that arise. Additionally, offering people the option of receiving a paper certificate of completion will satisfy those who prefer a more traditional form of recognition.

\section{Conclusion}

Though there is still much to be learned about using digital badges, this study sheds some light on perceptions and usage of them in professional learning in higher education. Although the majority of participants had a positive impression of the badges, finding them to be authentic and innovative, a sizable minority had lukewarm or negative impressions of them, and some viewed their digital badge as less prestigious than a paper certificate. Findings suggest that the badge's appearance affects its perceived credibility. Participants who indicated that they would use their digital badge identified a wide variety of uses, such as sharing them through social media and printing off a hard copy certificate. Others were uncertain about how they would use their digital badge. Many participants found the badges to be a motivator to continue the program, but not the sole reason to partake in professional learning development.

Since digital badges are still in the seminal stage, there is much to learn about good practices in professional learning development in higher education. Our findings shed some light on how they are perceived and used in this context.

Open Access This article is distributed under the terms of the Creative Commons Attribution 4.0 International License (http:// creativecommons.org/licenses/by/4.0/), which permits unrestricted use, distribution, and reproduction in any medium, provided you give appropriate credit to the original author(s) and the source, provide a link to the Creative Commons license, and indicate if changes were made.

\section{References}

Abramovich, S., Schunn, C., \& Higashi, R. M. (2013). Are badges useful in education? It depends upon the type of badge and expertise of the learner. Retrieved April 6, 2016 from http://www.lrdc.pitt.edu/ schunn/research/papers/Abramovich-Schunn-Higashi.pdf

Ahn, J., Pellicone, A., \& Butler, B. S. (2014). Open badges for education: What are the implications at the intersection of open systems and badging? Research in Learning Technology. Retrieved April 14, 2016 from http://webcache.googleusercontent.com/search?q= cache:Ra9tEYfazsIJ:www.researchinlearningtechnology.net/index. $\mathrm{php} / \mathrm{rlt} /$ article/view/23563+\&cd=1\&hl=en \&ct=clnk\&gl=ca

Anderson, T., \& Shattuck, J. (2012). Design-based research: A decade of progress in educational research? Educational Researcher, 41(1), 16-25. doi:10.3102/0013189X11428813 
Casilli, C., \& Knight, E. (2012). 7 things you should know about badges. EDUCAUSE. Retrieved from https://library.educause.edu/ resources/2012/6/7-things-you-should-know-about-badges

Cucchiarra, S., Giglio, A., Persico, D., \& Raffagheli, J. E. (2014). Supporting self-regulated learning through digital badges: A case study. In Y. Cao et al. (Eds.), ICWL Workshops, 133-142. doi: 10.1007/978-3-319-13296-9_15

Devedzic, V., \& Jovanovic, J. (2015). Developing open badges: a comprehensive approach. Educational Technology Research and Development, 63, 603-620. doi:10.1007/s11423-015-9388-3.

Elliot, R., Clayton, J., \& Iwata, J. (2014). Exploring the use of microcredentialing and digital badges in learning environments to encourage motivation to learn and achieve. In B. Hegarty, J. McDonald, \& S. K. Loke (Eds.), Rhetoric and reality: Critical perspectives on educational technology. Australasian Society for Computers in Learning in Tertiary Education (ASCILITE), Dunedin, NZ., 703-707.

Fields, E. (2015). Making visible new learning: professional development with open digital badge pathways. Partnership: The Canadian Journal of Library and Information Practice and Research, 10(1), 1-10.

Finkelstein, J., Knight, E., \& Manning, S. (2013). The potential and value of using badges for adult learners. American Institute for Research. Retrieved April 14, 2016 from https://lincs.ed.gov/publications/pdf/ AIR_Digital_Badge_Report_508.pdf

Gamrat, C., Zimmerman, H. T., Dudek, J., \& Peck, K. (2014). Personalized workplace learning: an exploratory study on digital badging within a teacher professional development program [electronic version]. British Journal of Educational Technology, 45(6), 1136-1148.

Gibson, D., Ostashewski, N., Flintoff, K., Grant, S., \& Knight, E. (2013). Digital badges in education. Education and Information Technologies, 20, 403-410. doi: 10.1007/s10639-013-9291-7

Glover, I. (2013). Open badges: A visual method of recognising achievement and increasing learner motivation. Student Engagement and Experience Journal, 2(1). doi: 10.7190/seej.vlil.66
Glover, D. \& Latif, F. (2013). Investigating perceptions and potential of open badges in formal higher education. World Conference of Educational Multimedia. Retrieved April 8, 2016 from http:// shura.shu.ac.uk/7173/1/Glover__Investigating_perceptions_and potential_of_open_badges_in_formal_higher_education_proceeding_- 112141.pdf

Hart, M. (2015). Badges: A new measure of professional development. Retrieved from http://campustechnology.com/Articles/2015/01/14/ Badges-A-New-Measure-of-Professional-Development.aspx? Page $=2$

Janzow, P. (2014). Connecting learning to jobs through digital badges. Catalyst, 42(2), 9-11.

Law, P., \& Law, A. (2014). Digital badging at the Open University: Recognition of formal and informal learning. The Open and Flexible Higher Education Conference: 'New Technologies and Future of Teaching and Learning.' Krakow, Poland.

McDaniel, R., Lindgren, R., \& Friskics, J. (2012). Using badges for shaping interactions in online learning environments. Paper presented at 2012 IEEE International Professional Communication Conference, Orlando, FL. doi:10.1109/IPCC.2012.6408619

Mehta, N. B., Hull, A. L., Young, J. B., \& Stoller, J. K. (2013). Just imagine: New paradigms for medical education. Academic Medicine, 88(10), 1418-1423. doi:10.1097/ACM.0b013e3182a36a07.

Mozilla Foundation \& Peer 2 Peer University. (2012). Open badges for lifelong learning: Exploring an open badge ecosystem to support skill development and lifelong learning for real results such as jobs and advancement. Working document. Retrieved April 6, 2016 from https://wiki. mozilla.org/images/b/b1/OpenBadges-Working-Paper_ 092011.pdf

University of Calgary. (2015). Course design program 2016. Retrieved April 6, 2016 from http://badges.ucalgary.ca/badges/36 